\title{
Respiratory effects of intraoperative alfentanil infusion in post-abdominal hysterectomy patients: A comparison of high versus low dose
}

\author{
Dirk G Snijdelaar, MD \\ Joel Katz, $\mathrm{PhD}$ \\ Michel Clairoux, MD FRCPC \\ Alan N Sandler, MBChB MSc FRCPC
}

\section{Summary}

A number of reports have been published describing (recurrent) respiratory depression after the use of alfentanil intraoperatively. To evaluate the severity of respiratory depression after the administration of alfentanil, 49 patients undergoing general anaesthesia for abdominal hysterectomy were randomly allocated to one of three groups and studied in a double-blind manner. During surgery patients received no opioids (group 1), low dose (group 2) or high dose of alfentanil (group 3). Postoperatively patients were monitored with pulse oximetry and respiratory inductive plethysmography. Postoperative pain was managed with PCA morphine.

Thirty-rine patients completed the study. Respiratory depressant effects were found in all three groups. A higher number of apnoeas (at. 60 minutes in group 1: $3.3 \pm 1.6$; group 2: $3.5 \pm 1.8$; group 3: $12.2 \pm 2.8$ ) and a higher mor phine consumption was found in group 2 when compared with group 1 and 3 . No differences were found among the groups in the other respiratory parameters or in terms of the number of patients with respiratory depression at ary one time. No cases of clear-cut recurrent respiratory depression were identified.

Keywords: opioids; alfentanil, intraoperative infusion; complications; respiratory depression

\section{Introduction}

Alfentanil has become popular as an opioid suitable for continuous infusion perioperatively. It has a shorter terminal elimination half-time than fentanyl $(\mathrm{t} 1 / 2 \beta$ of $70 \mathrm{~min})$ due to its smaller steady-state volume of distribution, although its hepatic clearance is also less than that of fentanyl1-3. Its short bloodbrain equilibration time results in rapid onset of analgesia. Alfentanil has been postulated to provide a better safety index with regard to postoperative respiratory depression than its analogues fentanyl and sufentanil when used perioperatively. Nonetheless

Acute Pain Research Unit, Department of Anaesthesla, The Toronto General Hospital, Toronto, Canada. Address for Corresponderice: Dirk G. Snijdelaar, University Medical Centre Nijmegen, Department of Anesthesiology, P.O. Box 9101, 6500 HB Nijmegen, The Netherlands, Tel.: + 31-24-3614576, Fax.: +3124-3613585.Emall: d.snijdelaar@anes.azn.nl there are several reports of respiratory depression in the early postoperative period after the use of alfentanil intraoperatively ${ }^{4-15}$. In all of these cases severe respiratory depression occurred some time after the patients were obviously fully recovered from anaesthesia. In most cases naloxone had to be given, after which rapid resumption of spontaneous respiration occurred. This phenomenon has been called recurrent, biphasic or delayed respiratory depression.

This study was performed to assess the preemptive analgesic effect of a high dose alfentanil infusion maintained throughout the intraoperative course. The findings of that aspect of the study are reported elsewhere ${ }^{16}$. It was also recognised that this study could provide valuable information as to the respiratory depressant effects of alfentanil in the postoperative period. Thus part of the study was designed to assess the severity of depression of ventilation in the first three postoperative hours. 


\section{Methods}

Ethical approval was obtained from The Toronto Hospital Committees for Research on Human Subjects. All patients gave their written informed consent to participate before entering the study.

\section{Patient selection}

Patients scheduled for abdominal hysterectomy were included in the study. Inclusion criteria were age 18 to 60 years, ASA physical status 1 or 2, body weight between 50 to $100 \mathrm{~kg}$, no significant central nervous system, respiratory, cardiac, hepatic or renal dysfunction, no previous allergies or adverse reactions with opioid analgesics, no history of opioid or substance abuse, and no history or symptoms of sleep apnoea syndrome.

\section{Randomisation and blinding procedures}

Before the start of the study, a computer generated randomisation schedule ${ }^{17}$ was used to specify the group ( 1 = no opioid, 2 = low dose alfentanil, $3=$ high dose alfentanil) to which each prospective patient would be assigned upon entry into the trial. An opaque envelope containing the group assignment was prepared, sealed and numbered for each prospective patient. On the morning of surgery, the anaesthetist in charge of the case opened the patient's envelope, read its contents, and prepared the syr inges of alfentanil for subsequent administration.

With the exception of the anaesthetist, who was responsible for the general anaesthesia, the patients and personnel who collected study data were blinded to the treatment.

\section{Preoperative assessment}

On the night prior to surgery, patients were farriliarised with the visual analogue pain scale (VAS) and introduced to the patient-controlled analgesia (PCA) pump (Abbott Life Care Infuser, Chicago, Illinois) and instructed in its use. Respiratory pattern was assessed continuously with respiratory inductive plethysmography (RIP - NIMS, Miami Beach, Florida) and haemoglobin oxygen saturation $\left(\mathrm{S}_{\mathrm{p}} \mathrm{O}_{2}\right)$ was continuously measured using pulse oximetry (Nellcor N-100, Nellcor Inc, Hayward, California) in the postoperative period (see 'Postoperative monitoring'). Baseline measurements of RIP and $\mathrm{SpO}_{2}$ were performed over a 30 minute period approximately 12 hours prior to surgery. Calibration and validation of the RIP - as well as its application in previous postoperative analgesic studies - have been described elsewhere ${ }^{18-20}$. Respiratory rate (RR), episodes of apnoea $(\mathrm{AP}=$ tidal volume of less than $100 \mathrm{ml}$ for more than 15 seconds) and episodes of slow respiratory rate $(\mathrm{SRR}=$ respiratory rate less than 8 breaths/min persisting for more than $5 \mathrm{rin}$ ) were measured continuously and recorded in five minutes epochs and calculated for each 30 minute interval. Patients were attended continuously by trained personnel during the entire preoperative and postoperative data collection periods. Respiratory pattern abnormalities were confirmed by the analysis of real-time respiratory inductive plethysmography output and direct observation of the patient. Episodes of desaturation $\left(\mathrm{SpO}_{2}<90\right.$ for 30 seconds) and the number of patients with respiratory depression $\left(\mathrm{SpO}_{2}<85 \%\right.$ for 30 seconds and/or a respiratory rate of less than 10 for more than 15 minutes) were also measured and the average $\mathrm{SpO}_{2}$ was calculated for each 30 minutes interval.

\section{General anaesthesia}

Patients were kept nil per os for six hours before surgery. All patients received diazepam per os (5-10 $\mathrm{mg})$ two hours prior to surgery as premedication. Patients were assigned at random to one of three groups.

For patients in group 1, anaesthesia was induced with midazolam (0.05 $\left.\mathrm{mg} \mathrm{kg}^{-1}\right)$ and thiopentone (3-5 $\left.\mathrm{mg} \mathrm{kg}{ }^{-1}\right)$. In all groups muscle relaxation and tracheal intubation was achieved with vecuronium $(0.1-0.15$ $\mathrm{mg} \mathrm{kg}{ }^{-1}$ ). Anaesthesia was maintained with $70 \% \mathrm{~N}_{2} \mathrm{O}$ in $\mathrm{O}_{2}$ and isoflurane. Opioids were not administered at induction or intraoperatively.

For patients in group 2, anaesthesia was induced with alfentanil $(30 \mu \mathrm{g} \mathrm{kg}-1)$, midazolam $(0.05 \mathrm{mg}$ $\left.\mathrm{kg}^{-1}\right)$, and thiopentone (3-5 $\left.\mathrm{mg} \mathrm{kg}^{-1}\right)$. Anaesthesia was maintained with $70 \% \mathrm{~N}_{2} \mathrm{O}$ in $\mathrm{O}_{2}$, isoflurane and bolus doses of alfentanil (10-20 $\left.\mu_{\mathrm{g} \mathrm{kg}} \mathrm{kg}^{-1}\right)$ every hour. For groups 1 and 2, isoflurane was titrated to maintain systolic blood pressure within $20 \%$ of baseline systolic blood pressure derived from preoperative ward measurements.

For patients in group 3, anaesthesia was induced with midazolam $\left(0.05 \mathrm{mg} \mathrm{kg}^{-1}\right)$ and alfentanil $(100 \mu \mathrm{g}$ $\mathrm{kg}^{-1}$ ). Anaesthesia was maintained with $70 \% \mathrm{~N}_{2} \mathrm{O}$ in $\mathrm{O}_{2}$ and a continuous infusion of alfentanil (1-2 $\mu_{\mathrm{g}}$ $\left.\mathrm{kg}^{-1} \mathrm{~min}^{-1}\right)$. The alfentanil dose was adjusted to maintain haemodynamic variables within $20 \%$ of preoperative ward values by administering a bolus 
dose of alfentanil $\left(10-20 \mu_{\mathrm{g}} \mathrm{kg}^{-1}\right)$ and increasing the alfentanil infusion by increments of $0.25-0.5 \mu_{\mathrm{g}} \mathrm{kg}^{-1}$ $\mathrm{min}^{-1}$. The alfentanil infusion was discontinued 30 minutes before the anticipated end of surgery. After induction of anaesthesia, all patients had a radial arterial catheter inserted for postoperative blood sampling to measure plasma alfentanil concentration, and (if necessary) to do blood gas analysis. Patients received propranolol $(0.5-1.0 \mathrm{mg})$ if tachycardia or hypertension was not controlled by the above regimens. At the conclusion of surgery, the trachea was extubated after emergence and upon resumption of spontaneous breathing. Patients received supplemental $\mathrm{O}_{2}$ by mask and were transported to the postanaesthetic care unit (PACU).

\section{Perioperative monitoring}

All patients were continuously monitored throughout the procedure with a non-invasive blood pressure cuff, electrocardiogram, pulse oximetry, temperature probe, nerve stimulator and end-tidal carbon dioxide and anaesthetic agent analyser. For groups 1 and 2 , mean end-tidal isoflurane concentration was calculated for each five minutes block after induction of anaesthesia until the end of surgery.

\section{Postoperative management}

Patients were assessed immediately upon arrival in the PACU. A PCA pump system was connected to the indwelling i.v. cannula. Every 10 minutes, patients were asked whether they were in need of pain relief. An affirmative response was followed by a $2.0 \mathrm{mg}$ intravenous bolus of mor phine administrated by the same nurse observer for all patients. The nurse observer was unaware of the group to which the patients had been assigned. This procedure was repeated until the patients were alert enough to begin using the PCA pump. The PCA pump was set to deliver a $1.5 \mathrm{mg}$ intravenous bolus of morphine with a lockout time of five minutes, a maximum dose of $30 \mathrm{mg}$ in any four hour period, and no continuous background infusion. This regimen was overseen by the Acute Pain Service (APS). APS personnel were unaware of the group to which the patients had been assigned. Morphine (mg) usage was calculated from hard copy records (Abbott TRW Printer Model TP 40).

\section{Postoperative pain measurement}

A $10 \mathrm{~cm}$ visual analogue scale (with endpoints labelled 'no pain' and 'worst possible pain') was used to assess pain intensity at rest (VAS-R) two and four hours after completion of surgery.

\section{Postoperative respiratory monitoring}

When the patient arrived in the PACU, pulse oximetry monitoring was reinstituted and the two transducer bands of the respiratory inductive plethysmography were attached around the rib cage and abdomen of the patient. Pulse oximetry and plethysmography were continued for three hours after surgery. Oxygen supplementation was routinely provided for the first 30 minutes in the PACU and then discontinued. If respiratory depression $\left(\mathrm{SpO}_{2}<85 \%\right.$ for 30 seconds or a respiratory rate of less than 10 for 15 minutes) occurred at any time an arterial blood gas sample was analysed. If the $\mathrm{SpO}_{2}$ persisted at $<90 \%$ after 30 seconds, supplementary oxygen was provided by face mask to provide an $\mathrm{SpO}_{2}$ of $>90 \%$.

\section{Plasma alfentanil concentration analysis}

Blood samples $(10 \mathrm{ml})$ were drawn in all patients from a radial artery at 30 minutes and 120 minutes after arrival in the PACU. Samples were collected in heparinised glass vials, centrifuged immediately, and the separated plasma stored at $-27^{\circ} \mathrm{C}$ until analysis at the end of the study. Assays were performed by a blinded technician on samples obtained from patients in groups 2 and 3 only. Concentrations of alfentanil were measured in duplicate using a specific radioimmunoassay kit (Janssen Biotech NV Research Products). The sensitivity of the assay is $0.1 \mathrm{ng} \mathrm{mll}^{-1}$ and the intraand inter-assay coefficients of variation covering the therapeutic range of concentrations were $<10 \%{ }^{21}$.

\section{Adverse effects}

Nausea and vomiting were treated as needed with dimenhydrinate $25-50 \mathrm{mg}$.

\section{Statistical analysis}

Demographic, clinical, and intraoperative treatment variables were analysed by $\chi^{2}$ test. (frequency data) or one-way, between-groups ANOVA (parametric data). VAS-R, morphine, plasma alfentanil concentrations, MRR, number of apnoeas, saturations, episodes of desaturation and number of patients with respiratory depression were analysed by two-way repeated measurements ANOVA using group and 


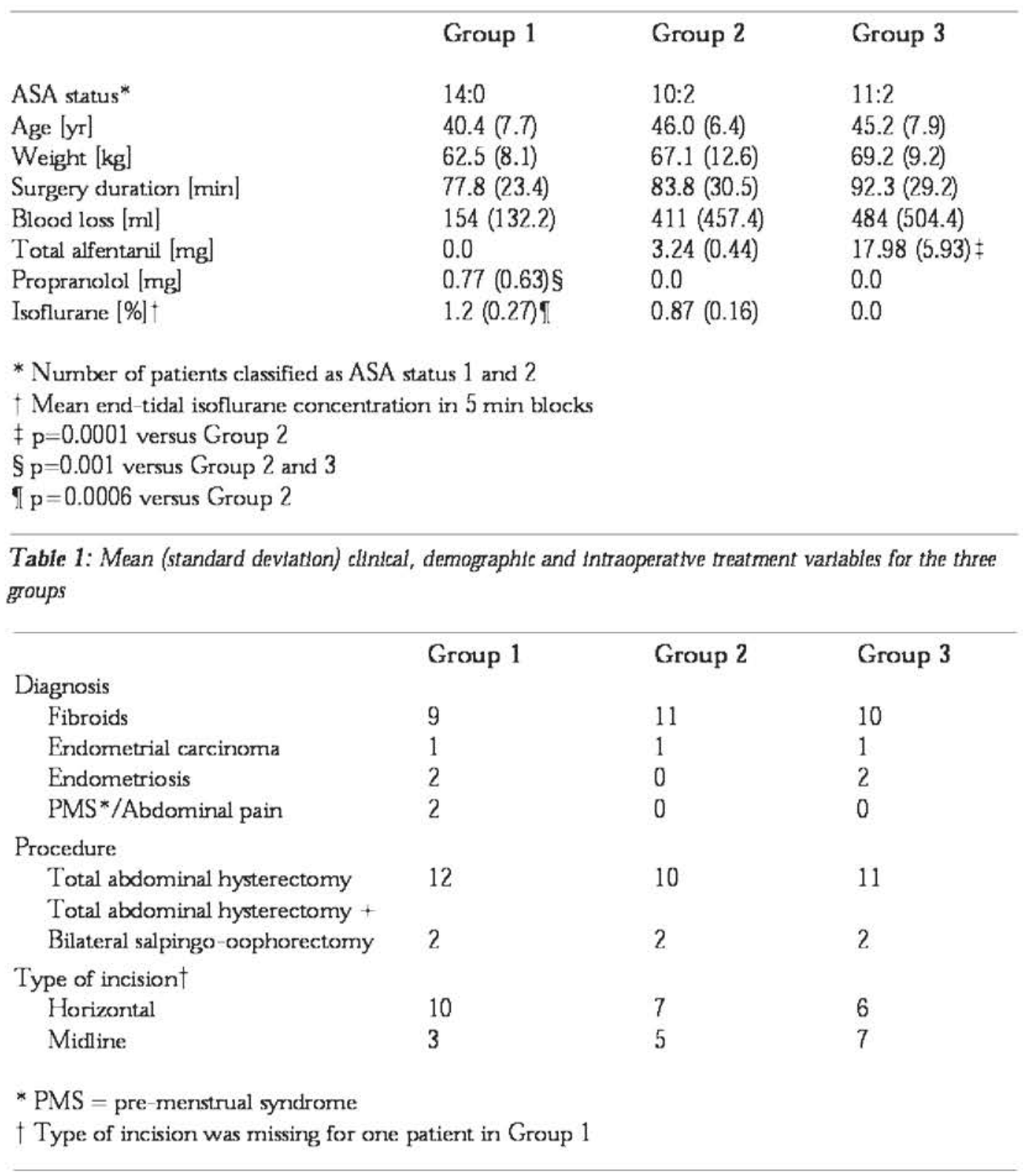

Table 2: Frequency of diagnosis, procedure and type of inciston for the three groups

the independent samples factor and time after surgery as the repeated measures factor. Significant effects were followed up with Fisher's protected LSD test to determine the pattern of differences between pairs of means. Currulative mor phine consumption was analysed by one-way ANOVA.

\section{Results}

\section{Patient withdrawals}

Forty-nine patients were recruited into the study. Three were removed for protocol violations, four for technical problems with the respiratory inductive plethysmograph monitoring equipment and three for lack of arterial blood sampling (no arterial catheter). Thirty-nine patients completed the study.

Demographic, clinical and intra-operative variables

The three groups did not differ significantly on demographic variables (Table 1) or in frequency of diagnosis, incision type or surgical procedure (Table 2). Group 3 received significantly more alfentanil than group $2(p=0.0001)$. Mean isoflurane requirements were significantly greater in group 1 than group $2(p=0.0006)$. Nine patients in group 1 received propranolol $(p=0.001)$. 


\begin{tabular}{llllll}
\hline & Group 1 & \multicolumn{2}{c}{ Group 2 } & \multicolumn{2}{c}{ Group 3 } \\
Time after surgery & VAS-R & VAS-R & ALF & VAS-R & ALF \\
30 minutes & $\mathrm{Nm}$ & $\mathrm{Nm}$ & $35(14.4)$ & $\mathrm{Nm}$ & $217(107.9) \dagger$ \\
2 hours & $6.2(1.9)$ & $5.9(1.4)$ & $19(10.9)$ & $4.0(1.9)^{*}$ & $147(93.3) \dagger$ \\
4 hours & $6.8(1.6)$ & $5.6(2.5)$ & $\mathrm{Nm}$ & $3.9(2.0)^{*}$ & $\mathrm{Nm}$ \\
& & & & & \\
$\mathrm{Nm}=$ Not measured & & & & & \\
${ }^{*} \mathrm{p} \leq 0.006$ versus Group 1 and 2 & & & & \\
$\dagger \mathrm{p}=0.0001$ versus Group 2 & & & & & \\
\end{tabular}

Table 3: Mean (standard deviation) VAS in rest (VAS-R) and mean (standard deviation) plasma alfentanil (ALF) concentrattons after surgery

\begin{tabular}{|c|c|c|c|c|c|c|c|}
\hline Group & $\begin{array}{l}\text { Number of } \\
\text { with respira }\end{array}$ & $\begin{array}{l}\text { atients } \\
\text { ry depression }\end{array}$ & $\mathrm{pH}$ & $\begin{array}{l}\mathrm{PO}_{2} \\
(\mathrm{mmHg})\end{array}$ & $\begin{array}{l}\mathrm{PCO}_{2} \\
(\mathrm{mmHg})\end{array}$ & $\begin{array}{l}\text { Plasma cc } \\
\text { of alfenta }\end{array}$ & $\begin{array}{l}\text { centrations } \\
\left(\mathrm{ng} \mathrm{ml}^{-1}\right)\end{array}$ \\
\hline 1 & $\begin{array}{l}\text { One episode } \\
0\end{array}$ & $\begin{array}{l}\text { Two episodes } \\
1\end{array}$ & $7.39(0.11)$ & $89(28.9)$ & $41(10.6)$ & $30 \mathrm{~min}$ & $60 \mathrm{~min}$ \\
\hline 2 & 2 & 1 & $7.34(0.03)$ & $83(11.0)$ & 54 (18.9) & $36(1.0)$ & $10(4.4)$ \\
\hline 3 & 0 & 3 & $7.29(0.05)$ & $108(71.0)^{*}$ & $49(5.5)$ & $189(26.8)$ & $127(20.3)$ \\
\hline
\end{tabular}

* Two patients in group 3 with respiratory depression received supplemental oxygen before the blood gas was drawn

Table 4: Number of patients with respiratory depression and the mean (standard deviation) results of thetr blood gas and plasma alfentanil analysts

Pain and morphine consumption

Over the four hour period, VAS-R pain scores (Table 3) were significantly lower in group 3 than in the other two groups $(\mathrm{p} \leq 0.006)$. Currulative morphine consumption (mg) at 180 minutes (Figure 1) was significantly lower in group 3 than in group 2 $(\mathrm{p}=0.02)$.

\section{Plasma concentration of alfentanil}

Plasma concentrations of alfentanil were available at 30 minutes and 120 minutes after surgery for 10 patients in group 2 and 10 patients in group 3 (Table 3). Mean alfentanil plasma concentrations in group 3 was significantly greater than that of group 2 at 30 and 120 minutes $(\mathrm{p}=0.0001)$.

\section{Postoperative respiratory monitoring}

The mean number of apnoeas (per 30 minutes) (Figure 2) in group 1 was significantly lower than in group 2 at $30(1.7 \pm 0.9$ versus $11.9 \pm 3.2$ for group 1 and 2, respectively) and at 60 (3.3 \pm 1.6 versus 12.2 \pm 2.8 for groups 1 and 2, respectively) minutes after surgery (all $\mathrm{p} \leq 0.007$ ). Moreover, at 60 minutes the mean apnoea rate in group $3(3.5 \pm 1.8)$ was sigrificantly lower than in group $2(p=0.007)$. From
90 minutes onward, there were no significant differences among the three groups. The mean respiratory rate (MMR) was significantly lower in group $3(14.7 \pm 1.0)$ than in group $1(20.9 \pm 1.2)$ at 30 minutes after surgery $(p=0.0002)$ (Figure 3). Thereafter MRR did not differ significantly among the groups. There was no significant difference among the groups in the mean number of slow respiratory rate episodes (SRR) or episodes of desaturation. Also no significant differences were found in terms of the number of patients with a respiratory depression at any one time (Table 4). It was noted in these patients that the respiratory depression occurred when the patients were asleep and that they were easily aroused by verbal stimuli.

Plasma concentrations of alfentanil did not differ significantly for patients with or without respiratory depression. There was no significant difference in average saturation although values for all three groups decreased significantly over time from 30 to 180 minutes after surgery $(p=0.0001)$ (Figure 4).

\section{Adverse effects}

No adverse effects (in terms of nausea and vorniting) were seen for the duration of the study. 


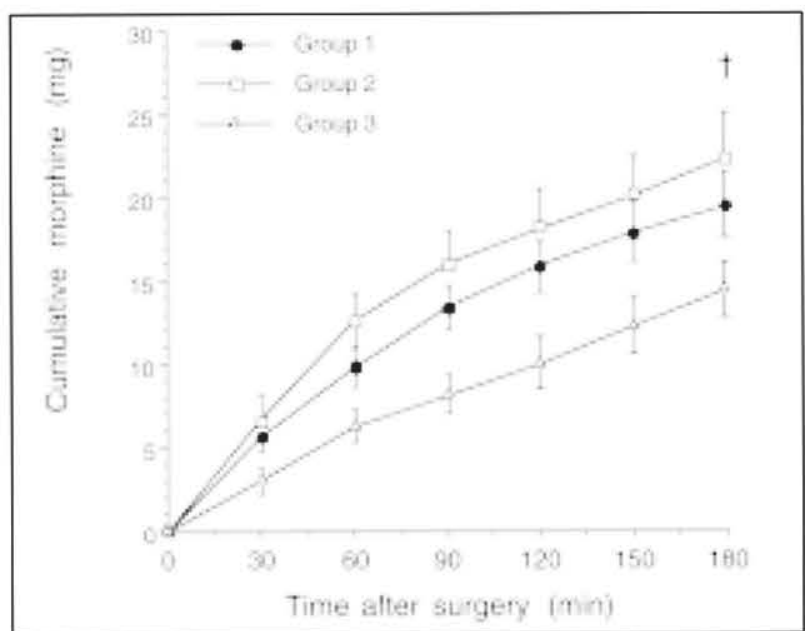

Figure 1: Cumulative PCA morphine consumption for the three groups. $t p=0.02$ for group 2 verus group 3

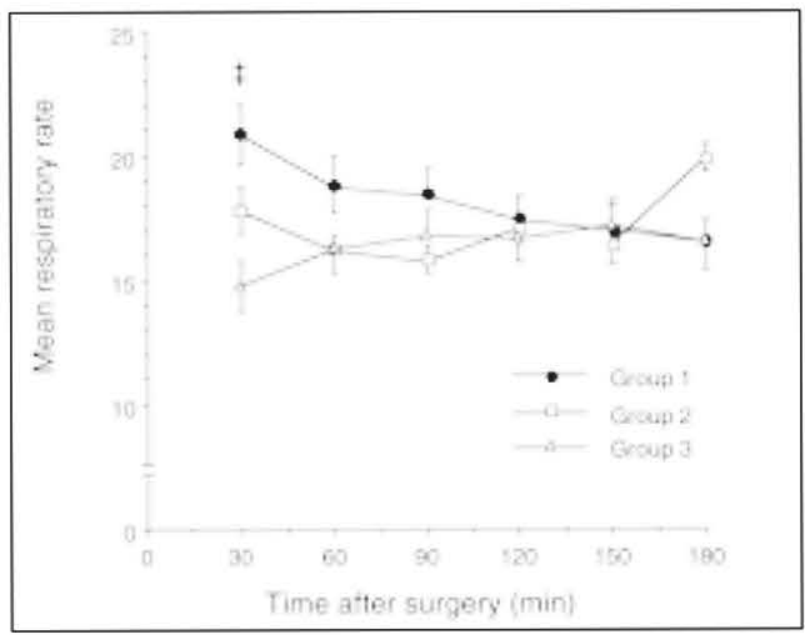

Figure 3: Mean respiratory rate for the three groups. $\ddagger p=0.0002$ for group 1 versts group 3

\section{Discussion}

The present study demonstrates that respiratory depression cccurred in at least one patient in all three groups. Ore patient in group 1. three patients in group 2 and three patients in group 3 experienced one or two episodes of respiratory depression as defined by a nespiratory rate lower than $10 / \mathrm{min}$ for 15 mirntes and/or saturation lower thar $85 \%$ for 30 seconds (see Table 4). It was roted in these patients that the respiratory depression occurred when the patients were asleep and that they were easily ancused by verbal stimuli

Diffenences were found among the groups in the mean respiratory rate, the number of apnceas. consumption of morphine and VAS-R.

The mear respiratory rate was lower in the high

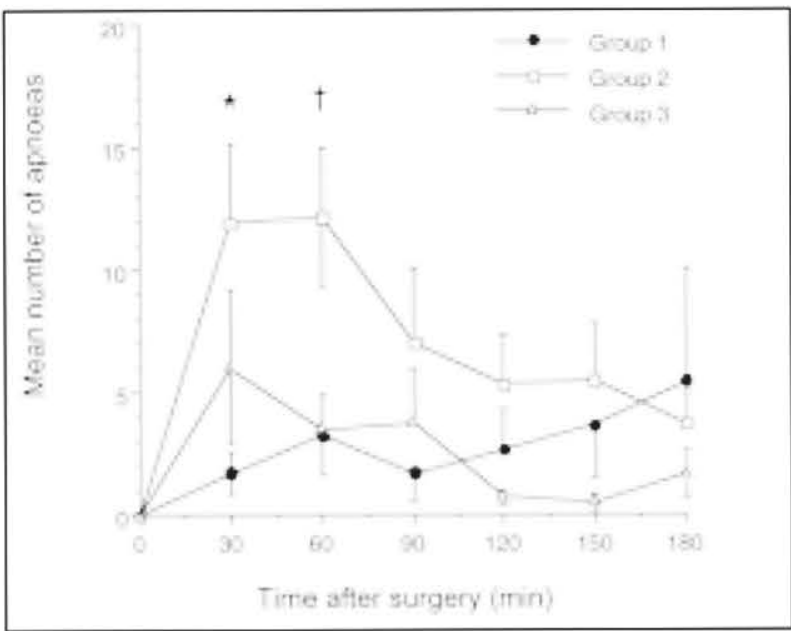

Fitgure 2: Mean number of apnoeas per 30 msnutes for the three groups. ${ }^{*} p=0.007$ for group 2 versus group 1 . $t_{p} \leq 0.007$ for group 2 versus group 1 and group 3

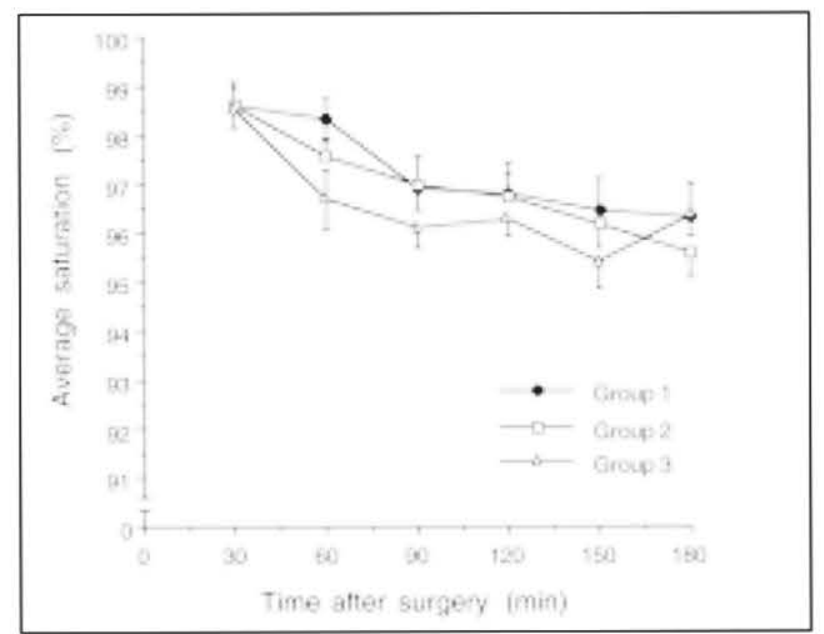

Figure 4: Average saturation (\%) for the three groups. Saturatson decreased significantly over ume for all three groups $(p=0.0001)$

dose alfentanil group (group 3) than in the nonopioid group (group 1) at 30 minutes. Since at that time point, the mean respiratory rate was 14.7 for group 3 and 20.8 for group 1, this was not considered to be of clinicel signiffcance.

The number of aproeas was found to be higher in group 2 than in group 1 at 30 minutes and in group 1 and 3 at 60 minutes after surgery. Furthermore the patients in group 2 had higher morphine consumption than the patients in group 3 in the first 90 minutes after surgery and a higher mean. VAS score during the first four hours after surgery. The finding of a higher number of apnceas in group 2 is rematkable, especially since no differences were found among the groups in the other respiratory parameters or in $\mathrm{SpO}_{2}$. Group 2 was the only group 
in which the patients received isoflurane and alfentanil during their general anaesthesia. Isoflurane is known to produce dose-dependent respiratory depression, although this effect is short-lived. It can be speculated that the finding of the higher number of apnoeas in group 2 is mainly caused by the higher morphine consumption combined with possible lingering effects of alfentanil.

Other studies also have tried to assess the problem of respiratory depression after the use of alfentanil. $\mathrm{CO}_{2}$ response curve measurements are a sensitive way to demonstrate respiratory depression ${ }^{22}$. Two open studies ${ }^{23,24}$ used this method to demonstrate that continuous infusion of alfentanil in patients resulted in depression of the $\mathrm{CO}_{2}$ response curve, but with a lesser effect on tidal volume, breathing frequency and $\mathrm{PCO}_{2}$ levels. Goldberg et a $!^{12}$ found that the $\mathrm{CO}_{2}$ response slopes were depressed for 120 minutes with a right shift of the slope in patients after an alfentanil-based anaesthetic. Mean plasma alfentanil concentrations ranged from $124.5 \mathrm{ng} \mathrm{ml}^{-1}$ at 30 minutes to $58.9 \mathrm{ng} \mathrm{m}^{-1}$ at 150 minutes. Secondary increases in plasma alfentanil concentrations in five out of 21 patients were found and eight patients experienced desaturation $\left(\mathrm{S}_{\mathrm{p}} \mathrm{O}_{2}<90 \%\right)$, but no relationship could be demonstrated between alfentanil plasma concentration and the $\mathrm{CO}_{2}$ response curve or arterial $\mathrm{O}_{2}$ desaturation. Also in Goldberg's study the episodes of desaturation most often occurred when the patients were asleep but arousable to verbal stimuli. Only one dose of alfentanil was used and no control group was included.

The disadvantage of using $\mathrm{CO}_{2}$ response curve measurements is that it requires active patient collaboration. Since each test must be performed with a large mouthpiece and nose clips, it creates some disturbance on awakening the subject and will counteract any respiratory depressant effects by arousing the patient. By using non-invasive and non interfering monitors such as inductive plethysmography and oximetry we tried to create a more realistic clinical PACU environment.

In the present study the highest mean plasma concentration of alfentanil measured was $217 \mathrm{ng} \mathrm{ml}^{-1}$ (in group 3 at 30 minutes after surgery). This value is in the range of the threshold for resumption of spontaneous breathing $\left(100-240 \mathrm{ng} \mathrm{ml}^{-1}\right)^{25}$. Plasma concentration of alfentanil did not differ between patients with or without respiratory depression. Cases of recurrent respiratory depression are described 4.8 which have occurred at a plasma concentration of $87 \mathrm{ng} \mathrm{ml}^{-1}$ and $95 \mathrm{ng} \mathrm{ml}^{-1}$. Sternlo et $a^{26}$ recently reviewed the published case reports of recurrent respiratory depression and found a very wide range in the alfentanil doses administrated (72$688 \mu \mathrm{g} \mathrm{kg}-1)$ and in the duration of the infusions (45 -465 minutes).

The cause of recurrent respiratory depression after the use of alfentanil remains unknown ${ }^{10}$. The different theories include:

- Secondary peaks in plasma concentrations of alfentanil have been demonstrated to occur 2,7,12. This can be caused by ' $\mathrm{pH}$ trapping', which irvolves the sequestration of the ionised drug in the acidic environment of the stomach with reabsorption in the non-ionised form in the (less acid) intestine. Also the postoperative release of alfentanil from the muscular compartment (becoming more active after surgery) may contribute to a secondary peak in the plasma concentration of alfentanil 7 . Both mechanisms have been described in the case of fentarny $1^{27,28}$. However, no studies have been published that specifically look at these mechanisms in the case of alfentanil.

- Alfentanil is known to have a large degree of interindividual variability in its pharmacokinetics. In the present study mean plasma concentrations of alfentanil were found to have large standard deviations (see Table 4). Obesity, age, variability in the level of $\alpha$-glycoprotein, decreased hepatic blood flow, changes in acidbase status and differences in the cytochrome P450 isozyms activity are possible factors responsible for the large interindividual differences in the pharmocokinetic profile of alfentanil 1,29,30. Furthermore it is known that drugs like propofol $1^{31,32}$, dexmedetomine ${ }^{33}$, erythromycin ${ }^{34}$, cimetidine ${ }^{35}$ and fluconazole ${ }^{36}$ can influence the clearance of alfentanil by interference in its metabolism.

- Patients that are alert and awake on arrival in the recovery room are usually 'left alone' because they seem to be doing well. This means that after extubation, transport to the PACU and the initial assessments on arrival in the PACU these patients may not receive any further stimulation. The decreased stimulation in these patients, combined with a lingering opioid effect, can be a factor in some cases of recurrent respiratory depression ${ }^{9,37}$. 
This theory is supported by the fact that most cases of recurrent respiration depression occurred 15 minutes or more after extubation ${ }^{26}$. Also the finding of very low $\mathrm{pH}$ values at the time of recurrent respiratory depression suggests that the respiratory depression evolved over some time ${ }^{8}$. In the present study and in the study of Goldberg et $a 1^{12}$, patients who had an episode of desaturation appeared to be asleep but could be easily aroused when stimulated.

In this controlled, randomised, double-blind study respiratory depressant effects were found in post abdominal hysterectomy patients who received no opioids, low or high doses of alfentanil during general anaesthesia. No cases of clear-cut recurrent respiratory depression were identified.

Supported by a grant from Janssen Research Foundation and grant \#MT-12052 from the Medical Research Council of Canada (JK). Presented in part at the Annual Meeting of the Canadian Anaesthetists Society, Ottawa, Ontario, 1995.

\section{References}

1. Bovill JG, Sebel PS, Blackburn CL, Heykants J. The pharmacokinetics of alfentanil (R39209): a new opioid analgesic. Anesthestology 1982; 57: 439-443.

2. Camu F, Gepts E, Rucquoi M, Heykants J. Pharmacokinetics of alfentanil in man. Anesth Analg 1982; 61: 657-661.

3. Hull CJ. The pharmacokinetics of alfentanil in man. Br J Anaesth 1983; 55 Suppl 2: 157S-164S.

4. Sebel PS, Lalor JM, Flynn PJ, Simpson BA. Respiratory depression after alfertanil infusion. BMJ 1984; 289: 1581-1582.

5. Lamarche Y, Martin R, Grenier Y. Continuous infusion of alfentanil for surgery. Can Anaesth Soc $J$ 1984; 31: S64-S65.

6. Raeder JC, Hole A. Alfentanil anaesthesia in gallbladder surgery. Acta Anaesthestol Scand 1986; 30: 35 40.

7. Reitz JA, Howie MB, Hoffer L, Kryc J, MacKichan JJ. The pharmacokinetics of alfentanil in gynecologic surgical patients. J Clin Pharmacol 1986; 26: 60-64.

8. Mahla ME, White SE, Moneta MD. Delayed respiratory depression after alfentanil. Anesthestology 1988; 69: 593-595.

9. Jaffe RS, Coalson D. Recurrent respiratory depression after alfentanil administration. Anesthestology 1989; 70: 151-153.

10. Krane BD, Kreutz JM, Johnson DL, Mazuzan JE, Jr. Alfentanil and delayed respiratory depression: case studies and review. Anesth Analg 1990; 70: 557-561.
11. Hudson RJ. Apnoea and unconsciousness after apparent recovery from alfentanil-supplemented anaesthesia. Can J Anaesth 1990; 37: 255-257.

12. Goldberg ME, Torjman M, Bartkowski RR, et al. Time-course of respiratory depression after an alfentanil infusion-based anaesthetic. Anesth Analg 1992: 75: 965-971.

13. Cassinello F, Peral A, Andueza A, Mourelle I. Respiratory depression after alfentanil. Anassthesia 1992; 47: 718.

14. Cartwright DP, Kvalsvik O, Cassuto J, et al. A randomized, blind comparison of remifentanil and alfentanil during anaesthesia for outpatient surgery. Anesth Analg 1997; 85: 1014-1019.

15. Calenda E, Muraine M. Recurrent respiratory depression after low doses of alfentanil. Eur $J$ Anaesthestol 1999; 16: 206.

16. Katz J, Clairoux M, Redahan $C$, et al. High dose alfentanil pre-empts pain after abdominal hysterectomy. Pain 1996; 68: 109-118.

17. Dallal GE. DESIGN: A supplementary module for SYSTAT and SYSGRAPH. Evanston, Illinois, U.S.A. SYSTAT, 1988.

18. Sandler AN, Baxter AD, Katz J, et al. A double-blind, placebo-controlled trial of transdermal fentanyl after abxdominal hysterectomy. Analgesic, respiratory, and pharmacokinetic effects. Anesthesiology 1994; 81: 1169-1180.

19. Sackner MA, Watson $H$, Belsito AS, et al. Calibration of respiratory inductive plethysmograph during natural breathing. J Appl Physiol 1989; 66: 410-420.

20. Sandler AN, Chovaz P, Whiting W. Respiratory depression following epidural morphine: a clinical study. Can Anaesth Soc J1986; 33: 542-549.

21. Michiels M, Hendriks R, Heykants J. Radioimmunoassay of the new opiate analgesics alfertaril and sufentaril. Preliminary pharmacokinetic profile in man. J Pharm Pharmacol 1983; 35: 86-93.

22. Read DJ. A clinical method for assessing the ventilatory response to carbon dioxide. Australas Ann Med 1967; 16: 20-32.

23. Andrews CJ, Sinclair M, Prys-Roberts C, Dye A. Ventilatory effects during and after continuous infusion of fentanyl or alfentanil. Br J Anaesth 1983; 55 Suppl 2: 211S-216S.

24. O'Connor M, Escarpa A, Prys-Roberts C. Ventilatory depression during and after infusion of alfentanil in man. $\mathrm{Br} J$ Anaesth 1983; 55 Suppl 2: 217S-222S.

25. Ausems ME, Hug CC, Jr., Stanski DR, Burm AG. Plasma concentrations of alfentanil required to supplement nitrous oxide anaesthesia for general surgery. Anesthestology 1986; 65: 362-373.

26. Sternlo JE, Sandin RH. Recurrent respiratory depression after total intravenous anaesthesia with propofol and alfertanil. Anaesthesta 1998; 53: 378-381. 
27. Stoeckel H, Hengstmann JH, Schuttler J. Pharmacokinetics of fentanyl as a possible explanation for recurrence of respiratory depression. Br J Anaesth 1979; 51: 741-745.

28. Hug CC, Jr., Murphy MR. Tissue redistribution of fentanyl and termination of its effects in rats. Anesthesiology 1981; 55: 369-375.

29. Scholz J, Steinfath M, Schulz M. Clinical pharmacokinetics of alfentanil, fentanyl and sufentanil. An update. Cin Pharmacoktnet 1996; 31: 275-292.

30. Kharasch ED, Thummel KE. Human alfentanil metabolism by cytochrome P450 3A3/4. An explanation for the interindividual variability in alfentanil clearance? Anesth Analg 1993; 76: 10331039.

31. Pavlin DJ, Coda B, Shen DD, et al. Effects of combining propofol and alferitanil on ventilation, analgesia, sedation, and emesis in human volunteers. Anesthestology 1996; 84: 23-37.
32. Janicki PK, James MF, Erskine WA. Propofol inhibits enzymatic degradation of alfentanil and sufentanil by isolated liver microsomes in vitro. $\mathrm{Br} J$ Anaesth 1992; 68: 311-312.

33. Kharasch ED, Hill HF, Eddy AC. Influence of dexmedetomidine and clonidine on human liver microsomal alfentanil metabolism. Anesthesiology $1991 ; 75: 520-524$.

34. Lemmens HJ. Pharmacokinetic-pharmacodynamic relationships for opioids in balanced anaesthesia. Cin Pharmacoktnet 1995; 29: 231-242.

35. Sedman AJ. Cimetidine-drug interactions. Am J Med 1984; 76: 109-114.

36. Palkama VJ, Isohanni MH, Neuvonen PJ, Olkkola KT. The effect of intravenous and oral fluconazole on the pharmacokinetics and pharmacodynamics of intravenous alfentanil. Anesth Analg 1998; 87: 190194.

37. Cohen AT. Respiratory depression after alfentanil infusion. BMJ 1985; 290: 319. 